\title{
Computed tomography morphometric analysis of anterior instrumentation in the pediatric thoracic spine
}

\author{
Yao Li, MD, Zhonghai Shen, MD, Xiangyang Wang, MD, PhD, Yongli Wang, MD, Hongming Xu, MD, \\ Feng Zhou, MD, Shaoyu Zhu, MD, and Huazi Xu, MD, PhD
}

Department of Orthopaedic Surgery, Second Affiliated Hospital of Wenzhou Medical University, Wenzhou, Zhejiang, China

\begin{abstract}
OBJECTIVE The authors' goal in this paper was to quantify reference data on the dimensions and relationships of the maximum posterior screw angle and the thoracic spinal canal in different pediatric age groups.

METHODS One hundred twelve pediatric patients were divided into 4 age groups, and their thoracic vertebrae were studied on CT scans. The width, depth, and maximum posterior screw angles with different screw entrance points were measured on a Philips Brilliance $16 \mathrm{CT}$. The statistical analysis was performed using the Student t-test and Pearson's correlation analysis.
\end{abstract}

RESULTS The width and depth of the thoracic vertebrae increased from T-5 to T-12. The width ranged from 18.5 to 37.1 $\mathrm{mm}$, while the depth ranged from 16.1 to $28.2 \mathrm{~mm}$. The maximum posterior screw angle decreased from T-5 to T-12 in all groups. The ranges and mean angles at the entrance points were as follows: initial entrance point, $6.9^{\circ}$ to $12.3^{\circ}$ with a mean angle of $9.1^{\circ}$; second entrance point, $20.6^{\circ}$ to $27.0^{\circ}$ with a mean angle of $24.2^{\circ}$; and third entrance point, $29.2^{\circ}$ to $37.5^{\circ}$ with a mean angle of $33.7^{\circ}$. There were no significant age-related differences noted for the maximum posterior screw angles.

CONCLUSIONS The angle decreased from T-5 to T-12. No significant age-related differences were noted in the maximum posterior screw angles. Screws should be placed between the initial and second points and parallel to the coronal section or at a slight anterior orientation.

http://thejns.org/doi/abs/10.3171/2015.6.PEDS14523

KEY WORDS pediatric spine; computed tomography; morphometric analysis; anterior instrumentation

$\mathrm{T}$ HE anterior instrumentation fixation system for thoracolumbar stabilization was first introduced by Dwyer $^{2}$ to correct idiopathic scoliosis in adolescents. With advancements in radiology and biomechanics, various internal fixation device systems have been developed, and most of them are composed of screws or plates and rods. ${ }^{6,8,13,18}$ However, regardless of the chosen fixation device, the anterior screws are always placed laterally or anterolaterally into the vertebral body. The anterior procedure carries a risk of injury to the neurovascular structures, and several studies reported that the vertebral screw

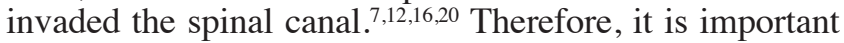
to understand the relationship between screw orientation and the spinal canal during anterior instrumentation placement.
In many earlier studies, $\mathrm{CT}$ imaging has been used to define the anatomical requirements of instrumentation and provide a guide for clinical practice within the spine, and these studies examined the relationship between the aorta and screw positions for the sake of accurate screw placement. ${ }^{1,14,17,21}$ In addition, some cadaveric anatomical studies on the anterior instrumentation of the thoracic and lumbar spine in adults have quantitatively evaluated the relationship between the screw placement angle and the spinal canal since the screw may penetrate the spinal canal if its angle exceeds the maximum., 3,4

To the best of our knowledge, no reports have documented the maximum posterior screw placement angle into the spinal canal in a pediatric population in order to consider age-dependent differences and other variations 
TABLE 1. Summary of group design

\begin{tabular}{ccccc}
\hline Group & Age $(\mathrm{yrs})$ & Male & Female & Total \\
\hline 1 & $7-9$ & 16 & 15 & 31 \\
\hline 2 & $10-12$ & 13 & 13 & 26 \\
\hline 3 & $13-15$ & 17 & 10 & 27 \\
\hline 4 & $16-18$ & 15 & 13 & 28 \\
\hline
\end{tabular}

in ossification. Thus, this CT-based morphometric analysis of pediatric patients grouped by age was performed to provide reference data and ensure safe anterior instrumentation in children.

\section{Methods}

\section{Clinical Materials}

This study was approved by our hospital's institutional review board. We retrospectively reviewed the thoracic spinal CT scans of Chinese pediatric patients who were treated at our institution between January 2005 and December 2013. The patients who had thoracic spinal abnor- malities, such as congenital deformities, trauma, or primary or secondary tumors, were excluded. The included children were classified into 4 groups (Table 1): Group 1 (7-9 years of age; 31 patients); Group 2 (10-12 years; 26 patients); Group 3 (13-15 years; 27 patients); and Group 4 (16-18 years; 28 patients).

\section{Measurement Methods}

The thoracic spine CT scans were performed using a Philips Brilliance 16 CT scan machine (Philips Medical Systems). The scan parameters included a layer thickness of 1.0 to $1.5 \mathrm{~mm}, 0.75$ to $1.5 \mathrm{~mm}$ collimation, $0.7 \mathrm{~mm}$ pitch, and a reconstruction level of $1 \mathrm{~mm}$. The original data were entered into an MXV workstation, and 2-dimensional image reconstruction was performed using multiplanar reconstruction methods. Bone windows were used for the analysis.

Vertebral width and depth were measured at each thoracic vertebra using the methods depicted in Fig. 1. The initial screw entrance point was set at the most anterior edge of the upper costal facet, while the second and third points were located $5 \mathrm{~mm}$ and $10 \mathrm{~mm}$ anterior to the initial point, respectively. The common point was located 3
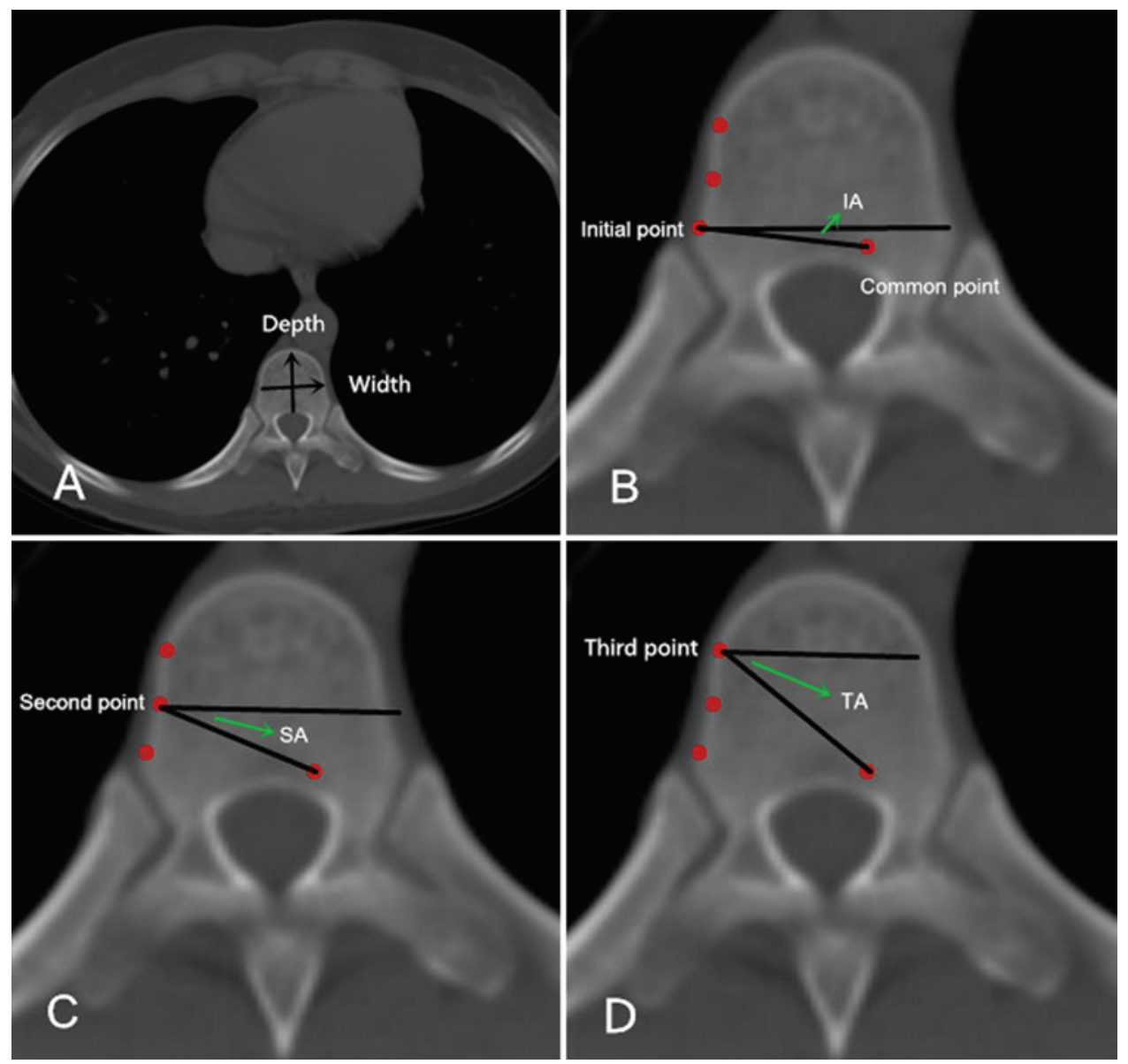

FIG. 1. Measurement of the thoracic vertebrae. Axial CT scan showing vertebral width and depth (A), and axial CT scan showing the maximum posterior screw angle at the level of the initial entrance point (IA) (B). The spot $5 \mathrm{~mm}$ anterior to the initial point (SA) is shown (C), and the spot $10 \mathrm{~mm}$ anterior to the initial point (TA) and the common point $3 \mathrm{~mm}$ anterior to the corner of the spinal canal are also shown (D). Figure is available in color online only. 
$\mathrm{mm}$ anterior to the contralateral corner of the spinal canal (Fig. 1). Thus, the line connecting the entrance point with the common point was defined as the screw trajectory, and the maximum posterior screw angle was measured between the screw trajectory line and the coronary horizontal line on the axial CT scan (Fig. 1). There were 3 maximum posterior screw angles: the initial entrance, second point, and third point. The position of the plane is parallel to the endplates in our study, and the length of the screws ranged from $25 \mathrm{~mm}$ to $35 \mathrm{~mm}$ in $5-\mathrm{mm}$ increments.

All measurements were collected and analyzed using an Excel spreadsheet (Microsoft). Graphical representations of our data were created using SPSS (version 16.0, SPSS Inc.). The mean values and standard deviations were calculated for all parameters. The sex differences in these parameters were examined using the independent t-test, while the correlation between age and angles was analyzed using the Pearson's correlation coefficient.

\section{Results}

The vertebral dimension measurements and maximum posterior screw angles at the different entrance points are described below.

\section{Vertebral Width}

The mean values and standard deviations for vertebral width are presented in Table 2. The vertebral widths increased from T-5 to T-12 in all groups. There were no significant differences between girls and boys at each level $(p>0.05)$. Age appeared to be associated with vertebral width ( $\mathrm{r}$ range: boys, 0.870-0.910; girls, 0.735-0.817; $\mathrm{p}<$ $0.05)$.

\section{Vertebral Depth}

The mean values and standard deviations for vertebral depths are presented in Table 3. The vertebral depths increased from T-5 to T-12 in all groups. There were no significant differences between girls and boys at each level $(p>0.05)$. Age appeared to demonstrate an associative effect, along with vertebral width ( $\mathrm{r}$ range: boys, 0.752 0.818; girls, 0.758-0.869; $\mathrm{p}<0.05$ ).

\section{Maximum Posterior Screw Angle}

The mean values and standard deviations for the maximum posterior screw angle at the initial screw entrance point are presented in Table 4. At the initial entrance point, the angles in boys and girls were $12.3^{\circ}$ to $6.9^{\circ}$ and $12.2^{\circ}$ to $7.0^{\circ}$, respectively. There were no significant differences between female and male patients at each level ( $\mathrm{p}$ $>0.05$ ). Age was not associated with the maximum posterior screw angle measured ( $\mathrm{r}$ range: boys, -0.003 to 0.324 ; girls, -0.106 to $0.410 ; \mathrm{p}<0.05)$.

The mean values and standard deviations for the maximum posterior screw angle at the second screw entrance point are presented in Table 5. At the second entrance point, the angle demonstrated a decreasing dimension from T-5 to T-12, and the angle in males and females ranged from $27.0^{\circ}$ to $20.9^{\circ}$ and $27.5^{\circ}$ to $20.6^{\circ}$, respectively. There were no significant differences between the female and male groups at any level $(\mathrm{p}>0.05)$. Age had no associative effect on the maximum posterior screw angle measured ( $\mathrm{r}$ range: boys, -0.072 to -0.294 ; girls, -0.163 to $-0.391 ; \mathrm{p}<0.05)$.

The mean values and standard deviations of the maximum posterior screw angle at the third screw entrance point are shown in Table 6. At the third entrance point, the angle decreased from T-5 to T-12, and the angles in the boys and girls were $37.4^{\circ}$ to $29.4^{\circ}$ and $37.5^{\circ}$ to $29.2^{\circ}$, respectively. There were no significant differences between the girls and boys at most levels $(p>0.05)$. Age was not associated with the maximum posterior screw angle ( $\mathrm{r}$ range: boys, -0.041 to 0.351 ; girls, -0.125 to -0.441 , $\mathrm{p}<$ $0.05)$.

\section{Discussion}

Anterior instrumentation fixation and fusion is a relatively new technique for the treatment of spinal disorders, including scoliosis, spondylolisthesis, fractures, tumors, and iatrogenic or degenerative instability. Compared with the traditional posterior approach to the spine, the anterior approach is considered a direct visualization and complete anterior decompression method. Therefore, anterior instrumentation is a viable option for the treatment of thoracic injury and deformity in children.

The use of anterior screws carries a significant risk of

TABLE 2. Thoracic vertebral width*

\begin{tabular}{|c|c|c|c|c|c|c|c|c|}
\hline \multirow[b]{2}{*}{ Vertebra } & \multicolumn{2}{|c|}{ Group 1 (7-9 yrs) } & \multicolumn{2}{|c|}{ Group 2 (10-12 yrs) } & \multicolumn{2}{|c|}{ Group 3 (13-15 yrs) } & \multicolumn{2}{|c|}{ Group 4 (16-18 yrs) } \\
\hline & Male & Female & Male & Female & Male & Female & Male & Female \\
\hline $\mathrm{T}-5$ & $19.8 \pm 1.3$ & $18.5 \pm 1.8$ & $21.4 \pm 1.4$ & $21.6 \pm 1.6$ & $24.7 \pm 1.7$ & $20.4 \pm 1.4$ & $26.4 \pm 1.9$ & $22.9 \pm 1.4$ \\
\hline T-6 & $20.7 \pm 1.5$ & $19.3 \pm 1.8$ & $22.2 \pm 1.3$ & $22.0 \pm 1.5$ & $25.7 \pm 2.0$ & $23.3 \pm 1.5$ & $27.7 \pm 1.9$ & $24.1 \pm 1.9$ \\
\hline $\mathrm{T}-7$ & $21.5 \pm 1.5$ & $20.0 \pm 1.8$ & $23.1 \pm 1.3$ & $22.8 \pm 1.4$ & $26.5 \pm 1.9$ & $24.6 \pm 1.5$ & $28.9 \pm 2.0$ & $25.1 \pm 2.0$ \\
\hline $\mathrm{T}-8$ & $22.5 \pm 1.5$ & $20.7 \pm 1.0$ & $24.0 \pm 1.3$ & $23.3 \pm 1.3$ & $27.9 \pm 2.0$ & $25.6 \pm 1.8$ & $30.0 \pm 1.6$ & $26.2 \pm 1.8$ \\
\hline T-9 & $23.5 \pm 1.5$ & $22.0 \pm 1.2$ & $24.9 \pm 1.3$ & $24.5 \pm 1.3$ & $29.4 \pm 1.9$ & $26.9 \pm 2.1$ & $31.1 \pm 1.8$ & $27.5 \pm 2.0$ \\
\hline $\mathrm{T}-10$ & $24.9 \pm 1.5$ & $23.6 \pm 1.7$ & $26.4 \pm 1.4$ & $25.8 \pm 1.6$ & $30.7 \pm 1.9$ & $28.5 \pm 2.1$ & $33.1 \pm 1.7$ & $28.8 \pm 2.0$ \\
\hline $\mathrm{T}-11$ & $26.4 \pm 1.7$ & $25.2 \pm 1.6$ & $28.6 \pm 1.7$ & $27.3 \pm 1.7$ & $33.5 \pm 2.3$ & $30.6 \pm 2.2$ & $35.5 \pm 2.1$ & $31.2 \pm 1.8$ \\
\hline $\mathrm{T}-12$ & $28.3 \pm 1.3$ & $27.0 \pm 1.4$ & $30.4 \pm 1.5$ & $29.2 \pm 1.5$ & $35.3 \pm 2.9$ & $32.7 \pm 2.5$ & $37.1 \pm 2.4$ & $33.5 \pm 1.5$ \\
\hline
\end{tabular}

\footnotetext{
* Values are shown in millimeters as the mean \pm SD.
} 
TABLE 3. Thoracic vertebral depth*

\begin{tabular}{|c|c|c|c|c|c|c|c|c|}
\hline \multirow[b]{2}{*}{ Vertebra } & \multicolumn{2}{|c|}{ Group 1 (7-9 yrs) } & \multicolumn{2}{|c|}{ Group 2 (10-12 yrs) } & \multicolumn{2}{|c|}{ Group 3 (13-15 yrs) } & \multicolumn{2}{|c|}{ Group 4 (16-18 yrs) } \\
\hline & Male & Female & Male & Female & Male & Female & Male & Female \\
\hline $\mathrm{T}-5$ & $17.8 \pm 1.6$ & $16.1 \pm 1.2$ & $18.7 \pm 1.7$ & $18.0 \pm 1.1$ & $20.7 \pm 1.8$ & $18.7 \pm 1.3$ & $21.6 \pm 1.6$ & $19.6 \pm 1.5$ \\
\hline T-6 & $18.5 \pm 1.2$ & $16.7 \pm 1.1$ & $19.5 \pm 1.9$ & $18.6 \pm 1.1$ & $21.9 \pm 2.0$ & $19.6 \pm 1.3$ & $22.6 \pm 1.3$ & $20.6 \pm 1.7$ \\
\hline T-7 & $19.3 \pm 1.3$ & $17.4 \pm 1.3$ & $20.3 \pm 1.1$ & $19.3 \pm 1.2$ & $22.8 \pm 2.1$ & $20.8 \pm 1.5$ & $23.7 \pm 1.3$ & $21.7 \pm 1.7$ \\
\hline $\mathrm{T}-8$ & $20.0 \pm 1.4$ & $18.0 \pm 1.3$ & $21.3 \pm 1.7$ & $20.3 \pm 1.2$ & $23.7 \pm 2.3$ & $21.8 \pm 1.6$ & $24.9 \pm 1.4$ & $22.6 \pm 1.6$ \\
\hline T-9 & $20.4 \pm 1.6$ & $18.4 \pm 1.5$ & $22.0 \pm 1.1$ & $20.9 \pm 1.2$ & $24.5 \pm 2.3$ & $22.5 \pm 1.8$ & $25.8 \pm 1.3$ & $23.5 \pm 1.6$ \\
\hline $\mathrm{T}-10$ & $20.9 \pm 1.8$ & $18.8 \pm 1.5$ & $22.7 \pm 1.1$ & $21.4 \pm 1.3$ & $25.2 \pm 2.1$ & $23.5 \pm 1.9$ & $26.7 \pm 1.3$ & $24.2 \pm 1.4$ \\
\hline $\mathrm{T}-11$ & $21.6 \pm 1.9$ & $19.4 \pm 1.6$ & $23.5 \pm 1.0$ & $22.0 \pm 1.5$ & $25.9 \pm 2.0$ & $24.2 \pm 1.9$ & $27.4 \pm 1.5$ & $25.0 \pm 1.4$ \\
\hline $\mathrm{T}-12$ & $22.4 \pm 1.9$ & $20.0 \pm 1.8$ & $24.2 \pm 1.8$ & $22.7 \pm 1.5$ & $26.9 \pm 1.9$ & $25.1 \pm 2.0$ & $28.2 \pm 1.8$ & $25.7 \pm 1.7$ \\
\hline
\end{tabular}

* Values are shown in millimeters as the mean \pm SD.

complications because of the proximity to the adjacent neurovascular structures. The thoracoscopic approach, in particular, is technically demanding in order to ensure optimal screw purchase. Huitema et al. ${ }^{7}$ reported that of 17 patients with idiopathic scoliosis treated with anterior instrumentation, 3 screws violated the spinal canal, and leg pain occurred at 3 and 15 months after surgery. Sucato et al. ${ }^{20}$ reported that 4 screws had penetrated into the spinal canal at a depth of $<2 \mathrm{~mm}$, but no neurological injuries resulted. No studies have determined the safe margins for spinal canal violation when performing anterior instrumentation in children. Gertzbein and Robbins ${ }^{5}$ reported that canal violation less than $4 \mathrm{~mm}$ by posterior pedicle screws is safe. In our study, we set the common point at 3 $\mathrm{mm}$ anterior to the contralateral corner of the spinal canal, and a screw trajectory in the spinal canal that connects the screw entrance point and common point is safe.

To establish the safety of anterior instrumentation, the optimal screw entrance point and screw orientation are the major factors that require consideration. Many studies reported using the most anterior edge of the costal facet as the landmark when placing anterior instrumentation, and the ideal anterior screw entrance point in scoliosis is just anterior to the rib head with a slightly anterior orientation. ${ }^{10,19,23}$ Zhang and Sucato ${ }^{22}$ found that the position of the rib head was changed from a more anterior position in the superior thoracic spine to a more posterior position in the caudal thoracic spine, and they suggested that a slightly anterior angle is required in the distal thoracic spine whereas a slightly posterior insertion angle is required for the proximal thoracic spine when the rib head is used as the starting point for anterior screw insertion. Qiu et al. ${ }^{17}$ recommended that the ventral excursion angle be no more than $5^{\circ}$ when the entry point is close to the rib head, and the screws be inserted into the vertebral body $5 \mathrm{~mm}$ anterior to the rib head with a $10^{\circ}$ ventral excursion angle or $10 \mathrm{~mm}$ anterior to the rib head with a $15^{\circ}$ to $20^{\circ}$ ventral excursion angle.

Several CT studies reported the importance of determining the relationship between the screw and neurovascular structures. Sucato et al. ${ }^{20}$ reported differences in the aortic position, in that the descending aorta is positioned more laterally and posteriorly in patients with scoliosis and the average distance from the posterior aspects of the screw to the spinal canal was $5.3 \mathrm{~mm}$. Kuklo et al. ${ }^{9}$ measured the distance and angle of the screw in the spinal canal and found that the screw-to-spinal-canal distance was an average of $5.3 \mathrm{~mm}$ with an average of $4.5^{\circ}$ from the coronal axis. By analyzing the CT scans from T-4 to T-12, Qiu et al. ${ }^{16}$ measured the angle for safe screw placementwhich is formed by the line passing the anterior edge of the bilateral rib head and the line from the anterior edge of the right rib head to the posterior wall of the aorta in the thoracic spine-and found that the angle ranged from

TABLE 4. Maximum posterior screw angle at the initial entrance*

\begin{tabular}{|c|c|c|c|c|c|c|c|c|}
\hline \multirow[b]{2}{*}{ Vertebra } & \multicolumn{2}{|c|}{ Group 1 (7-9 yrs) } & \multicolumn{2}{|c|}{ Group 2 (10-12 yrs) } & \multicolumn{2}{|c|}{ Group 3 (13-15 years) } & \multicolumn{2}{|c|}{ Group 4 (16-18 yrs) } \\
\hline & Male & Female & Male & Female & Male & Female & Male & Female \\
\hline $\mathrm{T}-5$ & $10.4 \pm 1.8$ & $10.2 \pm 1.9$ & $10.8 \pm 1.6$ & $10.5 \pm 1.1$ & $11.3 \pm 1.3$ & $10.3 \pm 1.5$ & $12.3 \pm 1.1$ & $12.2 \pm 1.5$ \\
\hline $\mathrm{T}-6$ & $9.4 \pm 1.0$ & $9.2 \pm 1.9$ & $9.5 \pm 1.6$ & $9.4 \pm 1.9$ & $10.6 \pm 1.9$ & $9.9 \pm 1.5$ & $11.2 \pm 1.0$ & $10.9 \pm 1.7$ \\
\hline $\mathrm{T}-7$ & $9.0 \pm 1.7$ & $8.8 \pm 1.2$ & $9.7 \pm 1.7$ & $9.5 \pm 1.8$ & $9.7 \pm 1.9$ & $9.0 \pm 1.8$ & $10.7 \pm 1.8$ & $10.3 \pm 1.6$ \\
\hline $\mathrm{T}-8$ & $8.9 \pm 1.8$ & $8.6 \pm 1.7$ & $9.2 \pm 1.7$ & $9.3 \pm 1.9$ & $8.9 \pm 1.1$ & $8.5 \pm 1.8$ & $10.0 \pm 1.8$ & $9.1 \pm 1.5$ \\
\hline T-9 & $8.8 \pm 1.8$ & $8.6 \pm 1.9$ & $8.6 \pm 1.8$ & $8.7 \pm 1.7$ & $9.3 \pm 1.1$ & $8.7 \pm 1.7$ & $9.3 \pm 1.9$ & $9.2 \pm 1.4$ \\
\hline $\mathrm{T}-10$ & $8.4 \pm 1.1$ & $8.2 \pm 1.8$ & $8.0 \pm 1.8$ & $8.0 \pm 1.7$ & $8.9 \pm 1.3$ & $9.6 \pm 1.9$ & $8.7 \pm 1.8$ & $8.7 \pm 1.5$ \\
\hline $\mathrm{T}-11$ & $7.8 \pm 1.8$ & $7.6 \pm 1.9$ & $7.5 \pm 1.3$ & $7.5 \pm 1.7$ & $8.2 \pm 1.6$ & $8.6 \pm 1.8$ & $7.9 \pm 2.0$ & $7.9 \pm 1.4$ \\
\hline $\mathrm{T}-12$ & $7.4 \pm 1.9$ & $7.6 \pm 1.0$ & $6.9 \pm 1.0$ & $7.0 \pm 1.7$ & $8.0 \pm 1.9$ & $7.9 \pm 1.9$ & $8.0 \pm 1.0$ & $7.7 \pm 1.6$ \\
\hline
\end{tabular}

\footnotetext{
* Values are shown in degrees as the mean \pm SD.
} 
Y. Li et al.

TABLE 5. Maximum posterior screw angle at the second point*

\begin{tabular}{|c|c|c|c|c|c|c|c|c|}
\hline \multirow[b]{2}{*}{ Vertebra } & \multicolumn{2}{|c|}{ Group 1 (7-9 yrs) } & \multicolumn{2}{|c|}{ Group 2 (10-12 yrs) } & \multicolumn{2}{|c|}{ Group 3 (13-15 yrs) } & \multicolumn{2}{|c|}{ Group 4 (16-18 yrs) } \\
\hline & Male & Female & Male & Female & Male & Female & Male & Female \\
\hline $\mathrm{T}-5$ & $26.7 \pm 1.2$ & $27.0 \pm 2.9$ & $27.0 \pm 1.4$ & $27.5 \pm 1.6$ & $26.3 \pm 1.7$ & $26.7 \pm 1.4$ & $26.2 \pm 1.1$ & $25.7 \pm 1.3$ \\
\hline T-6 & $26.1 \pm 1.1$ & $26.6 \pm 1.2$ & $26.1 \pm 1.1$ & $26.8 \pm 1.8$ & $25.3 \pm 1.3$ & $25.4 \pm 1.8$ & $25.7 \pm 1.1$ & $25.9 \pm 1.5$ \\
\hline $\mathrm{T}-7$ & $25.9 \pm 1.5$ & $25.9 \pm 2.8$ & $26.5 \pm 1.2$ & $25.9 \pm 1.8$ & $25.0 \pm 1.3$ & $24.9 \pm 1.7$ & $24.6 \pm 1.4$ & $24.7 \pm 1.1$ \\
\hline $\mathrm{T}-8$ & $24.6 \pm 1.8$ & $25.1 \pm 1.1$ & $25.0 \pm 1.4$ & $24.6 \pm 1.1$ & $24.4 \pm 1.6$ & $24.4 \pm 2.0$ & $23.7 \pm 1.8$ & $23.9 \pm 1.4$ \\
\hline $\mathrm{T}-9$ & $24.2 \pm 1.5$ & $24.2 \pm 1.4$ & $24.3 \pm 1.3$ & $24.5 \pm 1.5$ & $23.9 \pm 1.5$ & $23.5 \pm 1.5$ & $23.6 \pm 1.7$ & $23.4 \pm 2.0$ \\
\hline $\mathrm{T}-10$ & $23.1 \pm 1.2$ & $23.1 \pm 1.2$ & $23.5 \pm 1.5$ & $23.4 \pm 1.0$ & $23.8 \pm 1.2$ & $23.7 \pm 1.3$ & $23.5 \pm 1.1$ & $22.8 \pm 1.5$ \\
\hline $\mathrm{T}-11$ & $21.5 \pm 1.3$ & $21.5 \pm 2.2$ & $22.0 \pm 1.7$ & $22.9 \pm 1.3$ & $22.5 \pm 1.6$ & $22.1 \pm 1.5$ & $22.3 \pm 1.5$ & $21.6 \pm 1.6$ \\
\hline $\mathrm{T}-12$ & $20.9 \pm 1.4$ & $21.2 \pm 1.9$ & $22.1 \pm 2.0$ & $22.1 \pm 1.4$ & $22.6 \pm 1.5$ & $21.6 \pm 1.5$ & $21.2 \pm 1.0$ & $20.6 \pm 1.3$ \\
\hline
\end{tabular}

* Values are shown in degrees as the mean \pm SD.

$5^{\circ}$ to $35^{\circ}$, and the minimum angle was at T-7. In addition, radiological studies that refer to the posterior screw have been performed to ensure the safety and feasibility of using a posterior pedicle or translaminar screw, and these measurements provide a suitable screw angle and diameter for surgery. ${ }^{11,15}$ However, a thorough understanding of the relationship between the maximum posterior screw angles at different entrance points and the spinal canal in different age groups is still lacking.

In the present study, the vertebrae from T-5 to T-12 in the 4 age groups (7-18 years of age) were analyzed. A total of 896 vertebrae were measured in the present study, and the maximum posterior screw angle at the 3 screw entrance points was measured to determine the relationship between screw placement and safety in the spinal canal. The results show that the maximum posterior screw angles at the different screw entrance points demonstrated a consistently decreasing tendency in all groups. These findings are similar to those of a previous cadaveric anatomical study by Ebraheim et al. ${ }^{3}$ In addition, age had no associative effect on the maximum posterior screw angles measured.

We set the initial screw entrance point at the most anterior edge of the upper costal facet. At this entrance point, the maximum angle at T-5 $\left(10.2^{\circ}-12.3^{\circ}\right)$, which consistently decreased at $\mathrm{T}-12\left(6.9^{\circ}-8.0^{\circ}\right)$, changed to $20.6^{\circ}$ to $27.5^{\circ}$ at the second entrance point and $29.2^{\circ}$ to $37.5^{\circ}$ at the third entrance point. This study found that if the screw was placed more anteriorly, the margin of safety for the maximum posterior screw angle broadened. For a more posterior screw entrance point, the safety range of the posterior orientation angle is very narrow. When using the initial point as the starting point, the angle of the screw placement must be $<6.9^{\circ}$ or the screw may encroach the spinal canal, and placing the screw parallel to the coronal section or at a slight anterior orientation is better. Although the maximum posterior screw angle at the level of the third entrance point is wide, the relationship between the entrance point and the dimension of the vertebrae must be considered a problem. At the level of the superior thoracic spine, especially at T-5 and T-6 in patients between the ages of 7 to 12 years, the width ranged from $18.5 \mathrm{~mm}$ to $22.2 \mathrm{~mm}$ and the depth ranged from $16.1 \mathrm{~mm}$ to $19.5 \mathrm{~mm}$, which is so small that the third entrance point near the front edge of the vertebrae and the screw trajectory from the anterior to the posterior cannot be not recommended by the present study. ${ }^{19,23}$ In addition, there are many important structures, such as the azygous vein, descending aorta, and thoracic duct. Therefore, the third entrance point is not recommended for the superior thoracic spine.

Our study was limited by its design, which used a CT morphometric analysis of the relationship between the screw trajectory and the spinal canal in pediatric thoracic

TABLE 6. Maximum posterior screw angle at the third point*

\begin{tabular}{|c|c|c|c|c|c|c|c|c|}
\hline \multirow[b]{2}{*}{ Vertebra } & \multicolumn{2}{|c|}{ Group 1 (7-9 yrs) } & \multicolumn{2}{|c|}{ Group 2 (10-12 yrs) } & \multicolumn{2}{|c|}{ Group 3 (13-15 yrs) } & \multicolumn{2}{|c|}{ Group 4 (16-18 yrs) } \\
\hline & Male & Female & Male & Female & Male & Female & Male & Female \\
\hline $\mathrm{T}-5$ & $37.4 \pm 1.6$ & $37.3 \pm 1.1$ & $36.1 \pm 1.9$ & $36.1 \pm 1.4$ & $37.3 \pm 1.5$ & $37.5 \pm 1.4$ & $36.6 \pm 2.0$ & $36.3 \pm 4.6$ \\
\hline T-6 & $37.0 \pm 1.5$ & $37.1 \pm 1.4$ & $35.0 \pm 1.4$ & $35.3 \pm 2.3$ & $36.0 \pm 1.6$ & $36.5 \pm 2.0$ & $35.0 \pm 1.2$ & $35.8 \pm 1.6$ \\
\hline $\mathrm{T}-7$ & $36.5 \pm 1.8$ & $36.2 \pm 1.0$ & $34.9 \pm 1.6$ & $34.2 \pm 1.6$ & $35.4 \pm 2.0$ & $35.4 \pm 1.7$ & $34.4 \pm 1.8$ & $34.2 \pm 1.3$ \\
\hline $\mathrm{T}-8$ & $36.6 \pm 1.6$ & $36.1 \pm 1.8$ & $34.7 \pm 1.8$ & $34.5 \pm 1.4$ & $34.3 \pm 1.9$ & $34.9 \pm 1.9$ & $32.9 \pm 2.1$ & $32.5 \pm 1.4$ \\
\hline T-9 & $34.5 \pm 1.8$ & $34.5 \pm 1.8$ & $32.4 \pm 1.9$ & $32.8 \pm 1.4$ & $34.4 \pm 1.6$ & $34.1 \pm 1.5$ & $31.9 \pm 2.1$ & $32.7 \pm 2.0$ \\
\hline $\mathrm{T}-10$ & $34.5 \pm 1.7$ & $34.4 \pm 2.0$ & $31.0 \pm 1.9$ & $31.5 \pm 1.4$ & $32.3 \pm 1.4$ & $32.9 \pm 1.1$ & $31.9 \pm 1.7$ & $32.1 \pm 1.3$ \\
\hline $\mathrm{T}-11$ & $32.7 \pm 1.9$ & $32.9 \pm 2.3$ & $31.3 \pm 2.0$ & $31.7 \pm 1.4$ & $30.7 \pm 1.2$ & $30.7 \pm 1.7$ & $30.1 \pm 1.8$ & $30.2 \pm 1.7$ \\
\hline $\mathrm{T}-12$ & $30.2 \pm 2.1$ & $31.1 \pm 1.7$ & $29.6 \pm 2.1$ & $29.2 \pm 2.1$ & $29.5 \pm 1.5$ & $29.3 \pm 1.7$ & $29.4 \pm 1.3$ & $29.2 \pm 1.6$ \\
\hline
\end{tabular}

* Values are shown in degrees as the mean \pm SD. 
vertebrae rather than cadavers. Since the focus was patients with normal vertebrae, a future specific analysis on patients with abnormal anatomy is required to confirm our results.

\section{Conclusions}

Our investigation provides insight into the relationship between the maximum posterior screw angle and the spinal canal in order to ensure safe screw placement in the pediatric population. No significant age-related differences were noted in terms of the maximum posterior screw angles. Screws should be placed between the initial and second point parallel to the coronal section or at a slight anterior orientation.

\section{Acknowledgments}

This work is supported by a grant from the National Nature Foundation of China (Grant No. 81371988) and the Natural Science Foundation of Zhejiang Province for Distinguished Young Scholars (Grant No. R12H060001).

\section{References}

1. Bullmann V, Fallenberg EM, Meier N, Fischbach R, Schulte TL, Heindel WL, et al: Anterior dual rod instrumentation in idiopathic thoracic scoliosis: a computed tomography analysis of screw placement relative to the aorta and the spinal canal. Spine (Phila Pa 1976) 30:2078-2083, 2005

2. Dwyer AF: Experience of anterior correction of scoliosis. Clin Orthop Relat Res (93):191-206, 1973

3. Ebraheim NA, Xu R, Ahmad M, Yeasting RA: Anatomic considerations of anterior instrumentation of the thoracic spine. Am J Orthop 26:419-424, 1997

4. Ebraheim NA, Xu R, Urbancic R, Yeasting RA: Anatomic considerations for anterior instrumentation of the lumbar spine. Orthopedics 22:935-939, 1999

5. Gertzbein SD, Robbins SE: Accuracy of pedicular screw placement in vivo. Spine (Phila Pa 1976) 15:11-14, 1990

6. Hitchon PW, Goel VK, Rogge TN, Torner JC, Dooris AP, Drake JS, et al: In vitro biomechanical analysis of three anterior thoracolumbar implants. J Neurosurg 93 (2 Suppl):252-258, 2000

7. Huitema GC, van Rhijn LW, van Ooij A: Screw position after double-rod anterior spinal fusion in idiopathic scoliosis: an evaluation using computerized tomography. Spine (Phila Pa 1976) 31:1734-1739, 2006

8. Kaneda K, Abumi K, Fujiya M: Burst fractures with neurologic deficits of the thoracolumbar-lumbar spine. Results of anterior decompression and stabilization with anterior instrumentation. Spine (Phila Pa 1976) 9:788-795, 1984

9. Kuklo TR, Lehman RA Jr, Lenke LG: Structures at risk following anterior instrumented spinal fusion for thoracic adolescent idiopathic scoliosis. J Spinal Disord Tech 18 (Suppl):S58-S64, 2005

10. Lenke LG: Anterior endoscopic discectomy and fusion for adolescent idiopathic scoliosis. Spine (Phila Pa 1976) 28 (15 Suppl):S36-S43, 2003

11. Makino T, Kaito T, Fujiwara H, Yonenobu K: Analysis of lumbar pedicle morphology in degenerative spines using multiplanar reconstruction computed tomography: what can be the reliable index for optimal pedicle screw diameter? Eur Spine J 21:1516-1521, 2012

12. McAfee PC: Complications of anterior approaches to the thoracolumbar spine. Emphasis on Kaneda instrumentation. Clin Orthop Relat Res (306):110-119, 1994
13. McDonough PW, Davis R, Tribus C, Zdeblick TA: The management of acute thoracolumbar burst fractures with anterior corpectomy and Z-plate fixation. Spine (Phila Pa 1976) 29:1901-1909, 2004

14. Milbrandt TA, Sucato DJ: The position of the aorta relative to the spine in patients with left thoracic scoliosis: a comparison with normal patients. Spine (Phila Pa 1976) 32:E348-E353, 2007

15. Patel AJ, Cherian J, Fulkerson DH, Fox BD, Chern JJ, Whitehead WE, et al: Computed tomography morphometric analysis for translaminar screw fixation in the upper thoracic spine of the pediatric population. J Neurosurg Pediatr 7:383-388, 2011

16. Qiu Y, He YX, Wang B, Zhu F, Wang WJ: The anatomical relationship between the aorta and the thoracic vertebral bodies and its importance in the placement of the screw in thoracoscopic correction of scoliosis. Eur Spine J 16:1367-1372, 2007

17. Qiu Y, Wang WJ, Wang B, Zhu F, Zhu ZZ, Ng BK, et al: Accuracy of thoracic vertebral screw insertion in adolescent idiopathic scoliosis: a comparison between thoracoscopic and mini-open thoracotomy approaches. Spine (Phila Pa 1976) 33:2637-2642, 2008

18. Shimamoto N, Kotani Y, Shono Y, Kadoya K, Abumi K, Kaneda K, et al: Biomechanical evaluation of anterior spinal instrumentation systems for scoliosis: in vitro fatigue simulation. Spine (Phila Pa 1976) 26:2701-2708, 2001

19. Sucato DJ: Thoracoscopic anterior instrumentation and fusion for idiopathic scoliosis. J Am Acad Orthop Surg 11:221-227, 2003

20. Sucato DJ, Kassab F, Dempsey M: Analysis of screw placement relative to the aorta and spinal canal following anterior instrumentation for thoracic idiopathic scoliosis. Spine (Phila Pa 1976) 29:554-559, 2004

21. Wang W, Zhu Z, Zhu F, Wang B, Chu WC, Cheng JC, et al: The changes of relative position of the thoracic aorta after anterior or posterior instrumentation of type I Lenke curve in adolescent idiopathic thoracic scoliosis. Eur Spine J 17:1019-1026, 2008

22. Zhang H, Sucato DJ: Regional differences in anatomical landmarks for placing anterior instrumentation of the thoracic spine in both normal patients and patients with adolescent idiopathic scoliosis. Spine (Phila Pa 1976) 31:183-189, 2006

23. Zhang H, Sucato DJ, Welch RD: Anterior vertebral body screw position placed thoracoscopically: a function of anatomy and surgeon experience in a porcine model. Spine (Phila Pa 1976) 29:815-822, 2004

\section{Disclosures}

The authors report no conflict of interest concerning the materials or methods used in this study or the findings specified in this paper.

\section{Author Contributions}

Conception and design: X Wang, Li. Acquisition of data: Shen, HZ Xu. Analysis and interpretation of data: Shen, Zhou. Critically revising the article: YL Wang, HM Xu. Reviewed submitted version of manuscript: YL Wang, HM Xu. Statistical analysis: Zhu. Administrative/technical/material support: HM Xu.

\section{Correspondence}

Xiangyang Wang, Department of Orthopaedic Surgery, Second Affiliated Hospital of Wenzhou Medical University, 109 Xueyuanxi Rd., Wenzhou, Zhejiang 325027, China. email: 297406372@qq.com. 